\title{
Isolation, diagnosis of bacteria Xanthomonas axonopodis causing bacterial canker disease on citrus and resistance using antibiotics
}

\author{
Zahra Salem almashhadany \\ Department of biology / College of Education of Girls \\ University of Mosul, Mosul, IRAQ \\ Zahraasalim2010@uomosul.edu.iq
}

DOI: $10.33899 /$ edusj.2019.162977

Received
$11 / 11 / 2018$

\author{
Accepted \\ 29 / $01 / 2019$
}

\begin{abstract}
The study aimed at the determination of the pathogen of bacterial canker disease on citrus trees. The study showed that Xanthomonas axonopodis pv. citri was the major cause of the disease. The isolation process were carried by isolating 50 affected isolates obtained from various citrus fruit such as orange, lemon and tarring as well as some leaves and branches. For diagnosis, Morphological and biochemical tests were conducted. The sensitivity of these isolates was tested for six types of antibiotics; Azithromycin, Cefixime, Cefotaxime, Gentamycin, Streptomycin and Tetracycline. It was seen that all isolated bacteria were sensitive to all antibiotics. Cephotaxime showed the highest bacterial inhibition value $25 \mathrm{~mm}$, while Azithromycin showed the lowest one $11 \mathrm{~mm}$. The extract of 5 plants was also tested; onion, garlic, radish, grapes, and red pepper. Most of the used extracts affected the bacteria. The water extracted of the red pepper showed the highest inhibition value $(10 \mathrm{~mm})$ while the extracted water of grapes showed no inhibition value.
\end{abstract}

Keywords: canker disease, citrus, antibiotics, extracts. 


\title{
عزل و تثخيص بكتريا Citri \\ التقرح البكتيري على الحمضيات ومقاومتها باستعمال المضادات الحيوية
}

\author{
زهراء سالم المشهداني \\ قسم علوم الحياة / كلية التربية للبنات

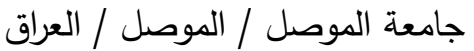 \\ Zahraasalim2010@uomosul.edu.iq
}

DOI: $10.33899 /$ edusj.2019.162977

القبول

الاستلام

2019 / 01 / 29

2018 / 11 / 11

\section{الخلاصة}

أجريت الدراسة بهدف تحديد مسبب مرض التقرح البكتيري على أشجار الحمضيات, وقد أثبتت الدراسة

أن البكتريا Xanthomonas axonopodis pv. citri هي المسبب الرئيس للمرض. وقد تم إجراء عمليات

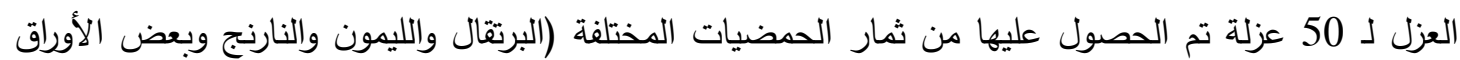
والأغصان) التي ظهرت عليها أعراض الإصابة، اجريت العديد من الاختبارات الثكلية والكيموحيوية لتشخيصها، واخذت هذه العزلات لـ 6 أنواع من المضادات الحيوية (ازثرومايسين Azithromycin، سيفيكسيم Cefixime، سيفوتاكسيم Cefotaxime، جنتامايسين Streptomycin : ستربتومايسين، تتراسايكلين Tetracycline Cefotaxime Azithromycin الفلفل الأحمر) وقد أعطت معظم المستخلصات المستعملة فعالية جيدة للبكتريا وكان المستخلص المائي للفلفل الأحمر أعلى قيمة تثبيط (10) ملم، بينما لم يظهر المستخلص المائي لنبات العنب أي فعالية.

الكلمات المفتاحية الدالة: التقرح البكتيري, الحمضيات, المضادات الحيوية, المستخلصات

\section{المقدمة}

تعد الحمضيات من نباتات الفاكهة والتي تعود إلى العائلة السذابيه Rutaceae جنس الحمضيات Citrus

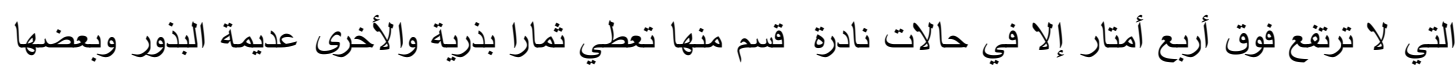

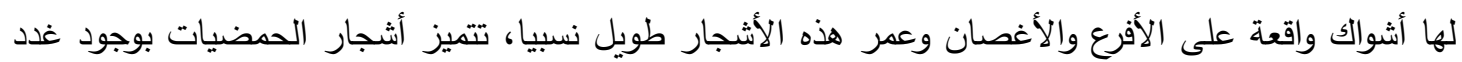

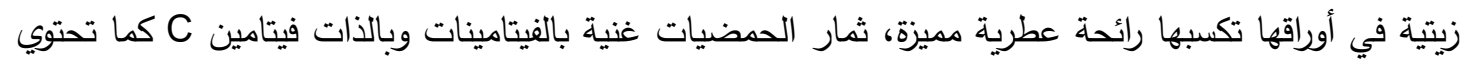
الثمار على فيتامين b1 و b2 b3 bما تحتوي على فيتامين A و الكاروتين ويوجد بثمار الحمضيات أحماض مثل حامض الستريك و الترتريك و البنزويك و السكسنيك و الاكساليك و الفورميك ايضا, كما أن ثمار

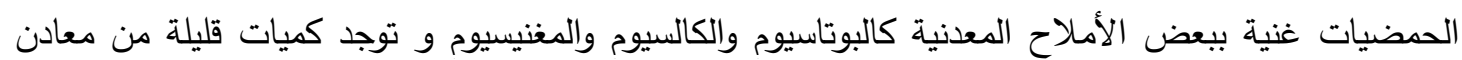
أخرى منها الفسفور والبروم والكلور واليود والبورون والحديد والصوديوم والنحاس (1). 
في العراق تتشثر زراعة اشجار الحضيات في جميع المناطق وتتركز في المنطقتين الوسطى والجنوبية بصوره ناجحة لملائمة الظروف المناخية والبيئية لزراعتها، وبالرغم من أهمية الحمضيات على اعتى اعتبارها احدى في فئي

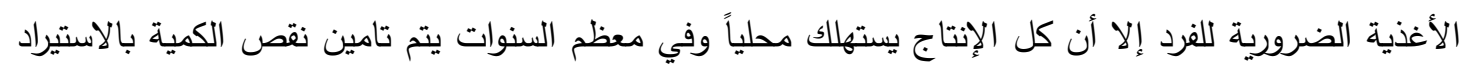

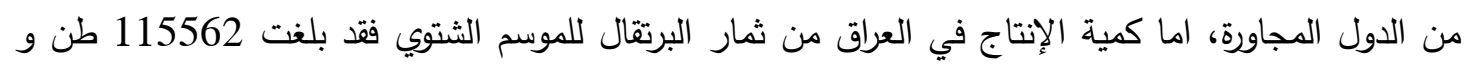

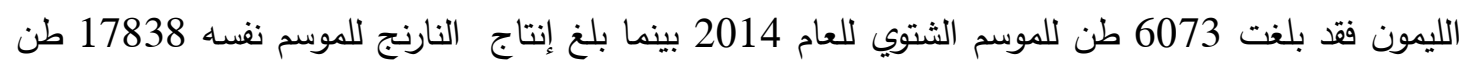
حسب تقرير إنتاج أشجار الحمضيات لعام 2014 (2). الأمراض البكتيرية التي تصاب بها الحمضيات قليلة مقارنة بالأمراض الفطرية و الفايروسية ولكن تعد

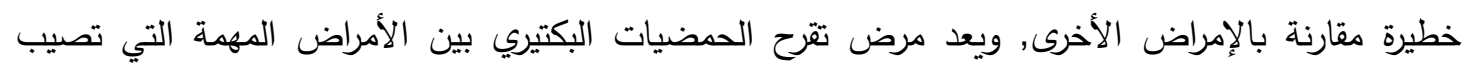
الحمضيات اذ تصيب البكتريا جميع أجزاء شجرة الحمضيات فوق سطح التربة كالأوراق والأغصان والجذانع وحتى الأنى الثرة وتنتهي بموت النبات بالكامل وتكون جميع الأنسجة في الحمضيات عرضة للإصابة وتعد البكتريا Xanthomonas axonopodis pv.citri

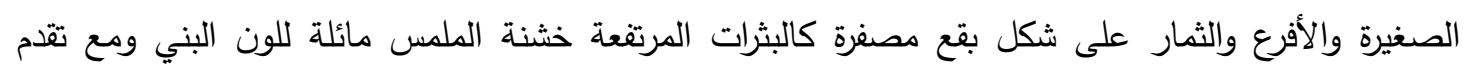
المرض تحاط هذه البثرات بهالة صفراء اللون وهذا ما يسمى عرض فوهة البركان (حافة عالية ووسط منخفض)

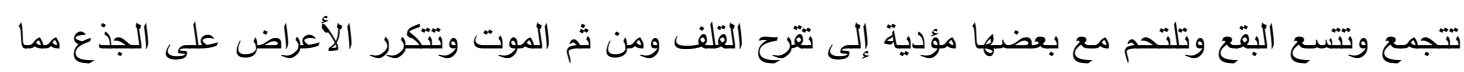
يؤدي إلى موت الفرع واصفرار الأوراق التي يحملها وتتساقط وفى النهاية (3).

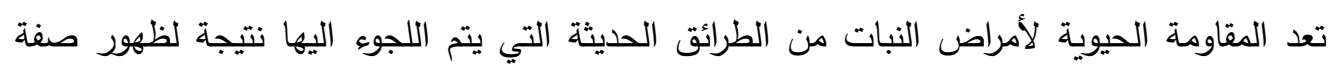
المقاومة لفعل المبيدات من قبل البكتريا وتزايد المخاوف الصحية المرتبطة بالمبيدات وتجنب تراكمها في البيئة مما دعت الحاجة إلى استعمالها وبالتحديد التضاد الحياتي بين الكائنات الحية الدقيقة بواسطة المواد التضادية المنتجة من البكتيريا أو الفطريات اذ انها تقلل من ضرر المركبات الكيميائية المتبقية على اجزاء النبات المختلفة كل ذلك ادى إلى زيادة الاهتمام في مقاومة أمراض النبات النمرئ (4).

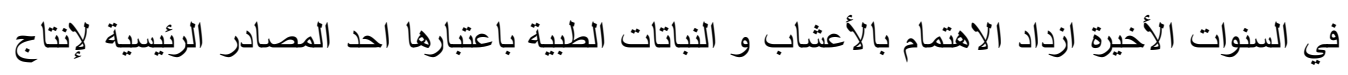

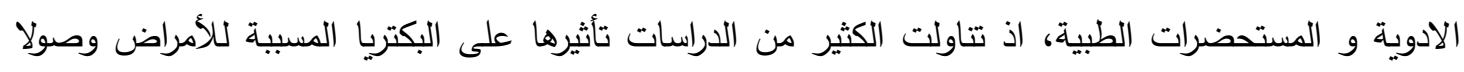

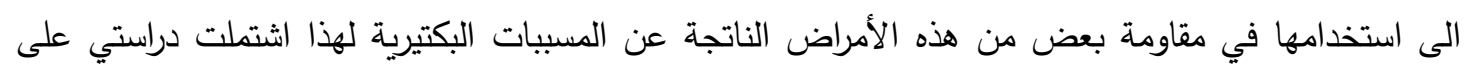

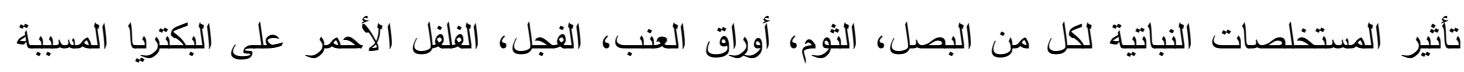
لمرض التقرح البكتيري للحمضيات (5). يشكل مرض التقرح البكتيري الخطر الحقيقي لزراعة الحمضيات في العديد من الأقطار والمهدد الحقيقي

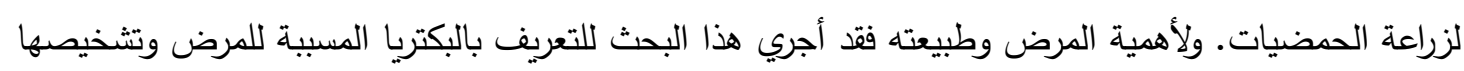
وتقييم بعض المضادات الملائمة والمستخلصات النباتية لمقاومتها.

\section{المواد و طرائق العمل}

\section{عزل و تثخيص المسبب المرضي: - ال}

جمعت 50 عينة من ثمار الحمضيات وهي من ثمار البرتقال والليمون والنارنج ومن أجزاء أخرى من النبات مثل الأوراق والأغصان التي ظهرت عليها أعراض الإصابة واجري العزل بأخذ قطع صغيرة بطول 0.5 
سم تقريبا وغمرت بمحلول الكحول 70\% لمدة 3 دقائق ثم نقلت القطع إلى الماء المقطر المعقم، بعد ذلك زرعت

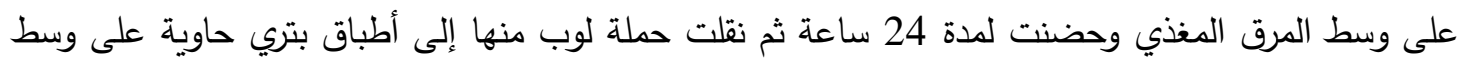
الأكار المغذي وحضنت الأطباق في درجة حرارة 28ْم لمدة 24 - 48 ساعة ولوحظت المستعمرات النامية.

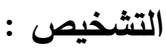

اجري التشخيص وذلك بإجراء الاختبارات الكيمو حيوية الآتية:

1- 1 - 1 - 1 اختبار صبغة كرام

أنشى غثاء بكتيري من المستعمرات النامية وصبغت الثرائح النامية بصبغة كرام وفحصت تحت

المجهر (6).

2- 20 - النمو بلرجة حرارة 39 م

أخذت حملة لوب من النمو البكتيري إلى سطح وسط الاكار المغذي Nutrient Agar و زرعة زرعت بطريقة

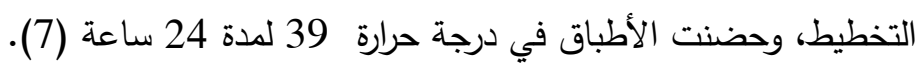

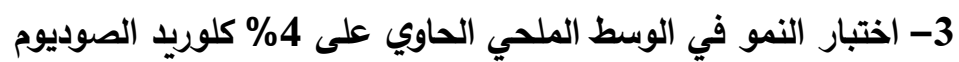

نقلت حملة من النمو البكتيري ولقحت بطريقة التخطيط على وسط الاكار المغذي الحاوي على 4 \% كلوريط الهوديد

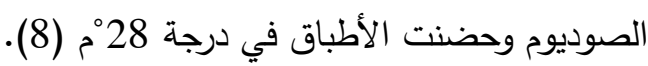

4 - النمو على الأوساط الاتخابية:

تم عزل البكتربا على وسط (NA) Nutrient Agar) ووسط مستخلص الخميرة والكلوكوز والاكار (YGC)

5east Extract D - Glucose Bacto Agar

5

الاختبارات الكيموحيوية التي أجريت هي:

اختبار الاندول و السترات و الاوكسديز و النترات و اختبار انتاج انزيم اليوريز و اختبارات السكريات

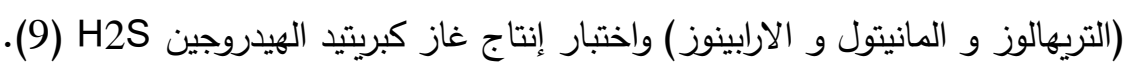

6- القدرة الإمراضية

استعملت طريقة الأوراق المنفصلة وذلك بأخذ اوراق سليمة من نبات النارنج وغسلت بماء الحنفية لمدة 10

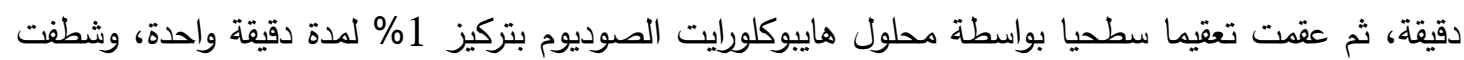

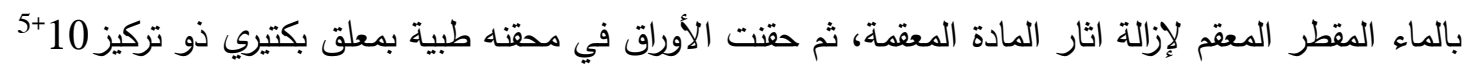

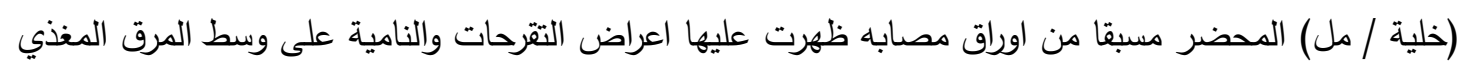
من مزرعة حديثة، ووضعت الأوراق الكاملة الملقحة في اطباق بتري حاوية على اوراق ترشيح معقمة مرطبة بالماء المقطر المعقم، ووضعت في حاضنة في درجة 28 مُ وفحصت يوميا لمدة سبعه ايام لملاحظة بداية ظهور التقرحات على الأوراق في حين لقحت معاملة المقارنة بالماء المقطر المعقم (10).

اختبار تأثير المضادات الحيوية في نمو البكتريا مختبريا:

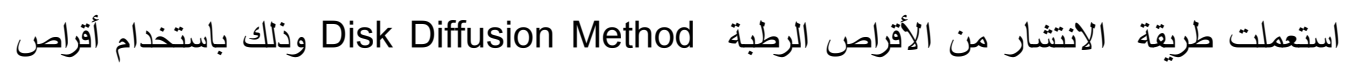
جاهزة من شركة Bio - Analyse التركية على وسط Mueller - Hinton agar والذي عقم بواسطة المعقام في درجة 121 لمدة 15 دقيقة ثم صب في أطباق بتري معقة وترك الوسط لكي يتصلب ثم لقح 
بالبكتريا بتركيز 10- 8 خلية بكتيرية. المحضرة مسبقا و النامية على وسط N B لمدة 24 ساعة وقد استخدمت 6 أنواع من المضادات الحيوية (الجدول 1) و حضنت الأطباق في درجة حرارة 28ْمَّم لمدة 24 - 28 ساعة ثم

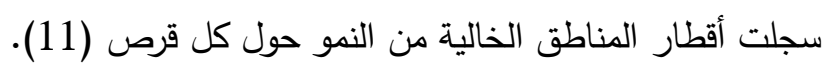

الجدول (1): المضادات الحيوية المستخدمة وتراكيزها ومختصراتها

\begin{tabular}{|c|c|c|}
\hline & تركيز المضاد(غرام /قرص ) & (المضيد| \\
\hline AZM & 15 & Azithromycin \\
\hline CFM & 5 & Cefixime \\
\hline CTX & 30 & Cefotaxime \\
\hline GN & 10 & Gentamycin \\
\hline S & 10 & Streptomycin \\
\hline TE & 10 & Tetracycline \\
\hline
\end{tabular}

اختبار حساسية البكتربا لمستخلصات النباتات:

استعملت طريقة الانتشار من الحفر Well Diffusion method في الأكار لاختبار حساسية البكتريا

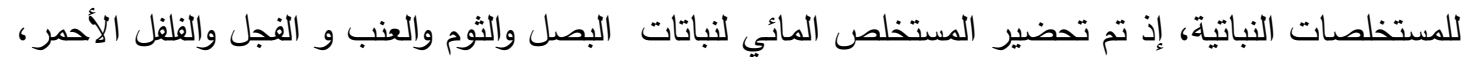

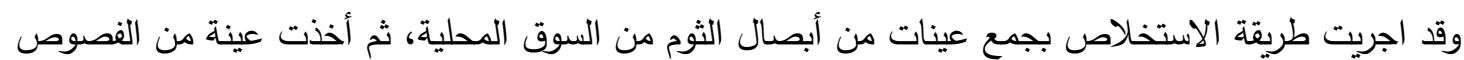
المقشرة بوزن 250 غم وخلطها بـ 250 مل من الماء المقطر المعقم المغلي، وتركت لمدة 10 دقائق، ثم مزج

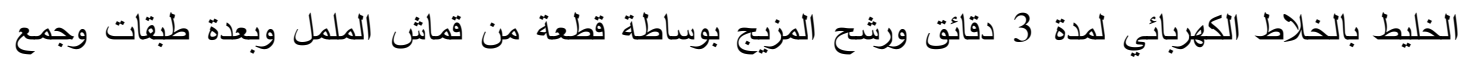
الراشح بقنينة زجاجية واصبح الراشح معدا للاستعمال و بتركيز 100\% بدون تخفيف (12).

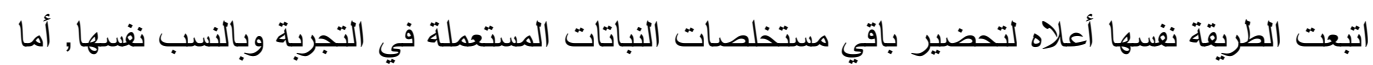
الأجزاء المستعملة من النباتات فهي موضحة في الجدول (2) وأخذت الرواشح وجرى تعقيمها بواسطة ورق ترشيح، ثم حضرت أطباق بتري حاوية على الوسط الغذائي N A، بعدها تم نشر المعلق البكتيري على الوسط بشكل كامل، وباستعمال ثاقب فلين معقم بقطر 0.5 سم تم عمل حفر في الوسط وبالاستعانة بمحقنة طبية تم وضع 0.5 مل في الحفر من كل مستخلص ووزعت بحيث يحوي الطبق الواحد على خمسة أنواع من المستخلصات وبواقع ثلاثة مكررات لكل مستخلص, اما معاملة المقارنة فقد ملئت حفرها بالماء المقطر المعقام, بعدها وضعت الأطباق جميعها في الحاضنة في درجة 28ْم لمدة 72 ساعة, وبعد انتهاء فترة التحضين اخذت النتائج بقياس قطر مناطق التثبيط حول كل حفرة.

\begin{tabular}{|c|c|c|}
\hline الجزء المستخدم & الاسم الشائع & الاسم العلمي للنبات \\
\hline الأوراق & البصل & Allium cepa \\
\hline الفصوص & الثثوم & Allium sativum \\
\hline 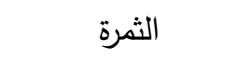 & الفلفل الأحمر & Capsicum annuum \\
\hline الجذر الجز & 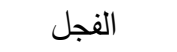 & Raphanus sativus \\
\hline الأوراق & العنب & Vitis amurensis \\
\hline
\end{tabular}


النتائج و المناقشة

$$
\begin{aligned}
& \text { عزل و تشخيص المسبب المرضي: } \\
& \text { العزل : }
\end{aligned}
$$

أظهرت نتائج العزل من ثمار البرتقال والليمون و النارنج والأجزاء النباتية المصابة منها نمو البكتيريا على

وسط الاكار المغذي كما مبين بالثكل (1).

$$
1 \text { - التشخيص: } 1 \text { - اختبار صبغة كرام: }
$$

يوضح الجدول (3) نتائج اختبارات تشخيص البكتريا المعزولة من العينات المصابة وتؤكد بان العزلة

البكتيرية هي Xanthomonas axonopodis وقد أظهرت نتائج صبغ البكتريا بصبغة كرام وفحصها تحت لتسات المجر الضوئي أن الخلايا البكتيرية هي كروية الثكل سالبة لكرام.

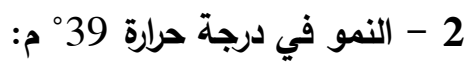

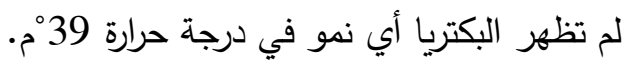$$
3 \text { - النمو في الوسط الملحي: }
$$

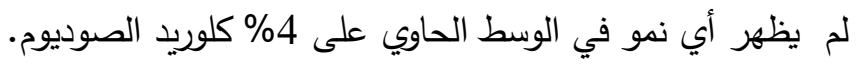

4 - النمو على الأوساط الانتخابية:

ظهرت مستعمرات صفراء ذات قوام لزج والتي تضمنت النمو على وسط NA كما في الثكل (1)

ووسط مستخلص الخميرة والكلوكوز والاكار YGC كما في الشكل (2).

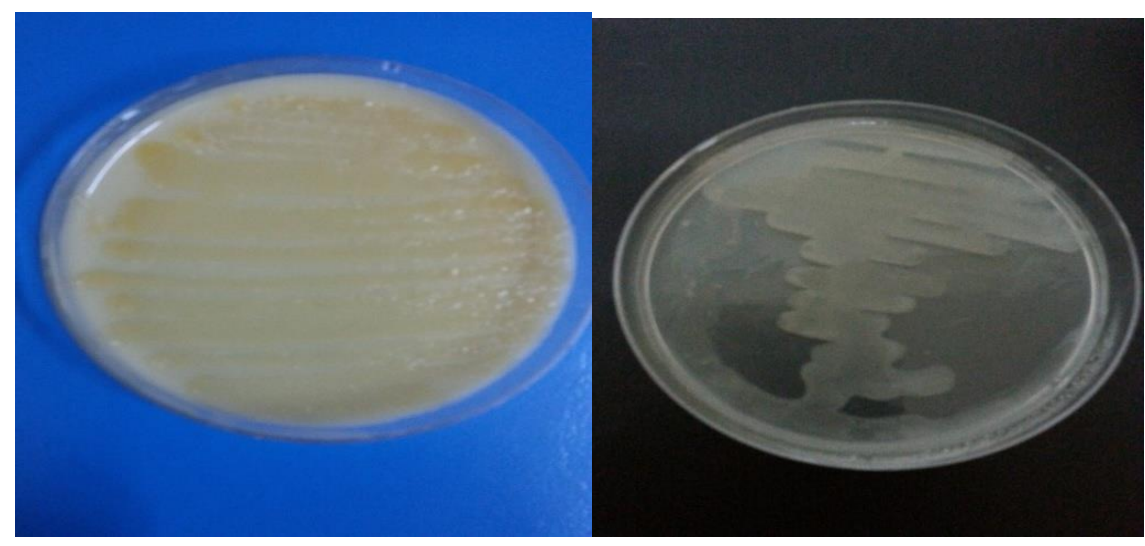

الثكل(2) (2) (- n)

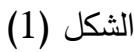

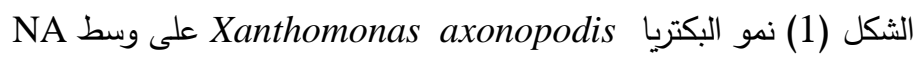

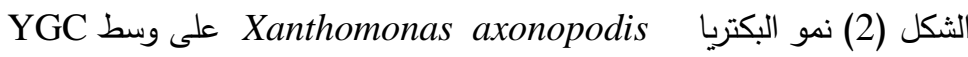

5

أعطت نتائج الاختبارات نتيجة سالبة لاختبار الأندول اذ أنها لم تكون حلقة الأندول الحمراء وبينما أعطت العزلات نتيجة موجبة لاختبار السترات وقامت بتغيير لون الوسط الأخضر وأعطت نتيجة موجبة أيضا

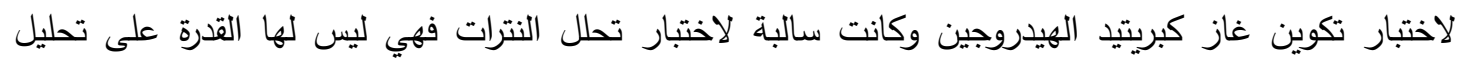
النترات إلى نتريت وكانت النتيجة سالبة لاختبار اليوريز وأعطت نتيجة موجبة لاختبارات السكريات وخاصنة المانيتول والتريهالوز والارابينوز • 
Xanthomona axonopodis الجدول (3): الاختبارات الكيموحيوية لتشخيص البكتريا

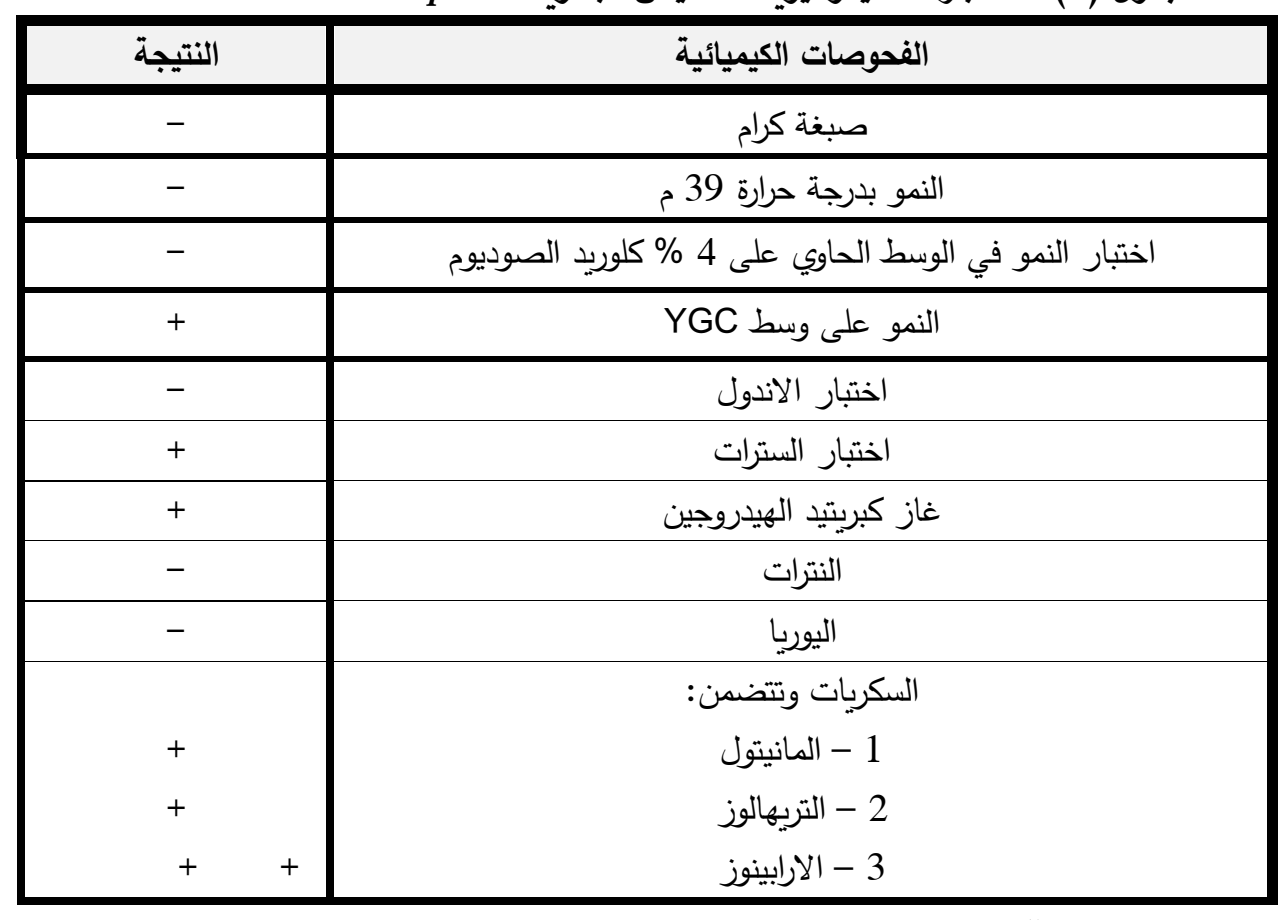

+ موجب, - سالب

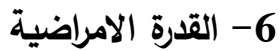

اظهر اختبار الامراضية على اوراق النارنج تحول في لون النسيج النباتي من الاخضر إلى البني المائل

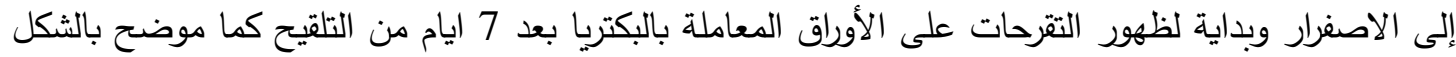

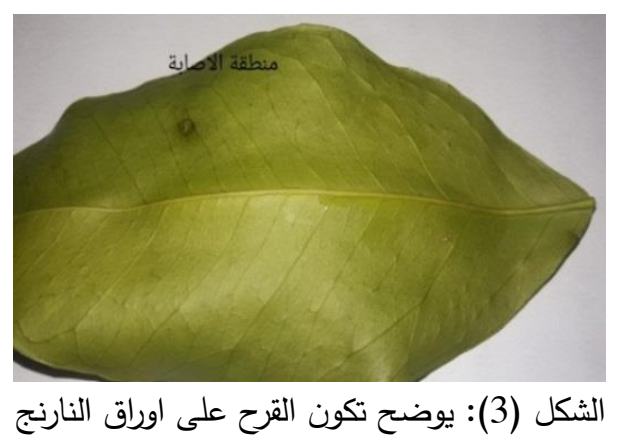

حساسية البكتربا للمضادات الحيوية

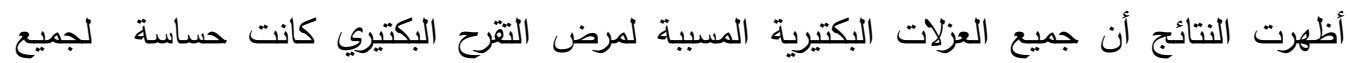

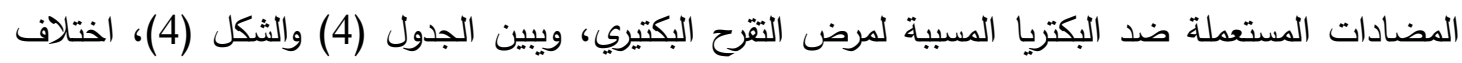
استجابة البكتريا للمضادات المستعملة قيد الدراسة, ويعد المضاد الحيوي سيفوتاكسيم Cefotaxime هو الأكثر

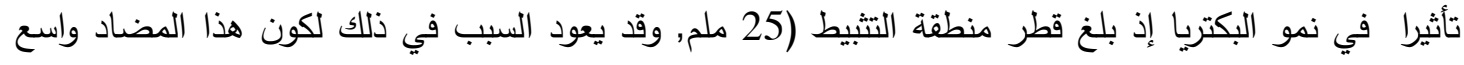
الطيف، ويعود إلى فئة السيفالوسبورينات (الجيل الثالث) وهو فعال ضد البكتريا السالبة كما انه يقتل البكتريا

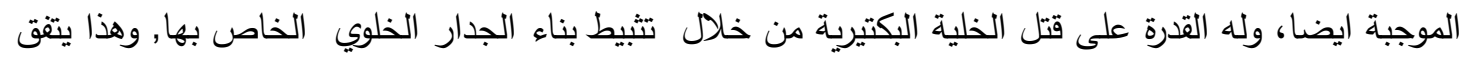

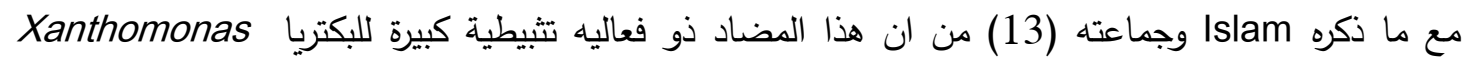
axonopodis 
ملم, وهو يعود إلى عائلة السيفالوسبورينات أيضا، وقد بينت نتائج التحليل الاحصائي وجود فروق معنوية بين المضاد سيفوتاكسيم والمضاد Cefixim والمضادات الاخرى أما المضادات الحيوية تتراسايكلين Tetracycline,

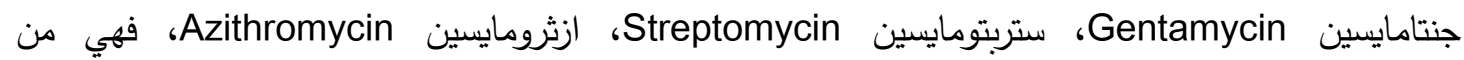

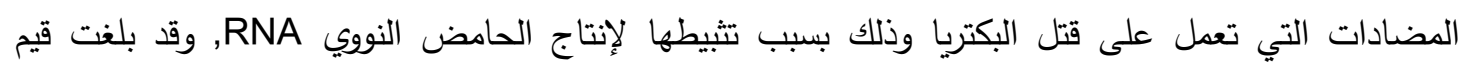

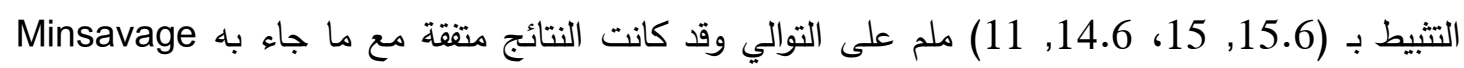

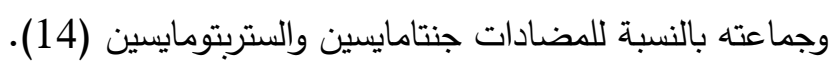

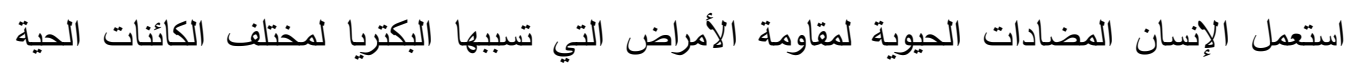

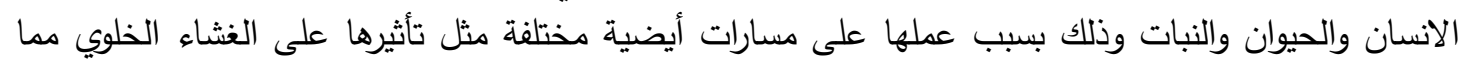

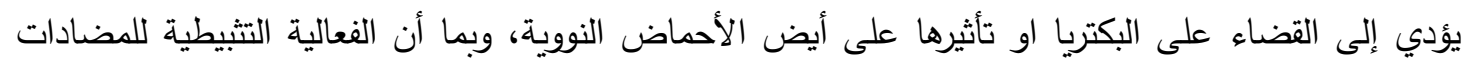

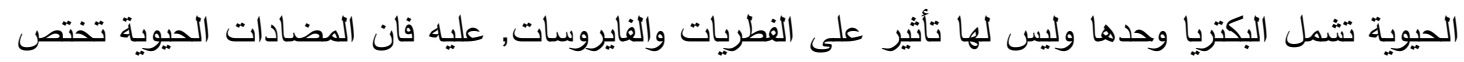
بمعالجة الإصابات البكتيرية وحدها (15).

الجدول (4): حساسية البكتريا للبكتريا Xanthomonas axonopodis المسببة لمرض تقرح الحمضيات للمضادات

\begin{tabular}{|c|c|}
\hline قطر منطقة التثبيط / ملم & المضاد الحيوي \\
\hline $11.000 \mathrm{~b}$ & Azithromycin \\
\hline $22.7667 a^{*}$ & Cefixime \\
\hline $25.000 \mathrm{a}$ & Cefotaxime \\
\hline $15.000 \mathrm{~b}$ & Gentamycin \\
\hline $14.600 \mathrm{~b}$ & Streptomycin \\
\hline $15.633 \mathrm{~b}$ & Tetracycline \\
\hline
\end{tabular}

* الارقام التي تحمل ارقاما متثابهة تدل على عدم وجود فروق معنوية عند مستوى احتمال 0.01 حسب اختبار دنكن افقيا وعموديا. تمثل معدل 3 مكررات.

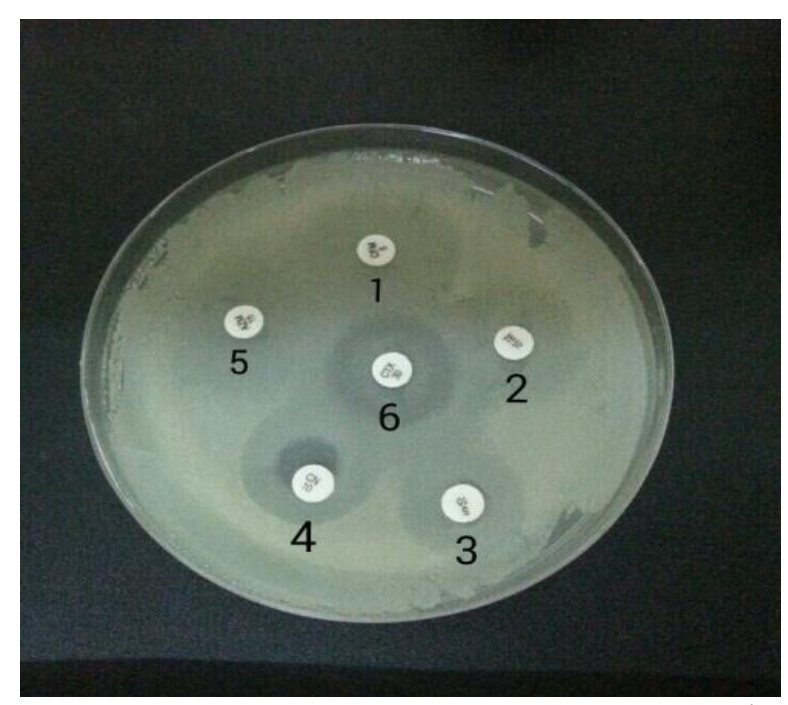

Xanthomonas axonopodis الثكل (4): يبين التأثير التثبيطي للمضادات الحيوية في البكتريا

Tetracycline -2

Gentamycin -4

Cefotaxime -6
Cefixime -1

Streptomycin -3

Azithromycin -5 
اختبار حساسية مستخلصات النباتات على البكتريا

يبين الجدول (5) أن المستخلص المائي للفلفل الأحمر كان له اكبر الأثر في تتبيط نمو البكتريا المسبية

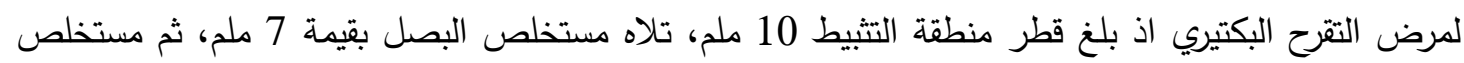

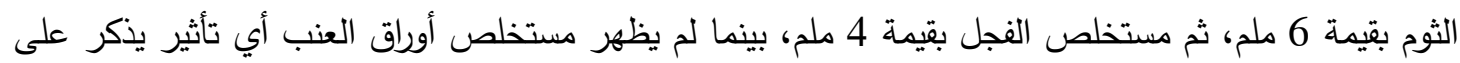

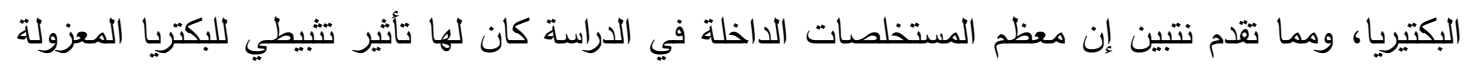
ولعل تفوق مستخلص الفلفل الأحمر على بقية مستخلصات النباتات إلى احتواءه على مادة الكابسايسن capsaicin فتعود إلى احتواء فصوص الثوم على مادة الالسين وهي مادة مضادة للتأكسد ولها القدرة على تثبيط البكتريا

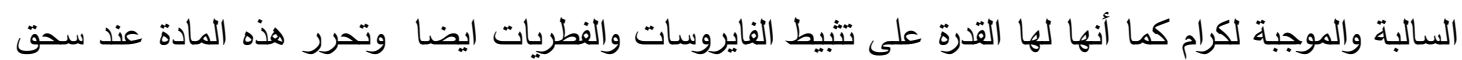
فصوص الثوم اثثاء عملية الاستخلاص وهذا يتفق مع ما وجده كل من سلمان وعلاء (16)، ومما تقدم يتبين أن للمستخلصات تأثير تثبيطي ولكنه اقل اذا ما قورن بفعالية المضادات الحيوية ذلك أن للمستخلصات التهات النباتية

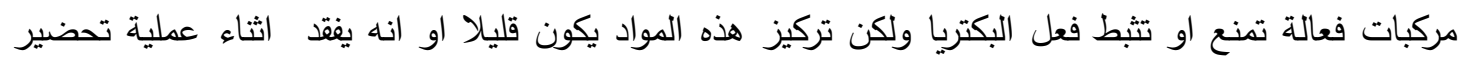
المستخلص أو خزن المستخلص وهذا يتقق مع ما ذكره مجيد والثطي (5 )، وأما انعدام التأثير التثبيطين لمستخلص أوراق العنب فانة يمكن أن يعود إلى مادة البوليفينول الموجودة في أوراق العنب والتي لها فائدة كبيرة في مجال الحفاظ على البشرة من التجاعيد والثيخوخة ولكن ليس لها مواد مثبطة لنمو البكتريا وهذا يتفق مع إنى ISlam الفلفل الاحمر وبقية المستخلصات الاخرى.

الجدول (5): حساسية المستخلصات النباتية للبكتريا

\begin{tabular}{|c|c|}
\hline قطر منطقة التثبيط & النباتات المستعملة \\
\hline $7.0 \mathrm{~b}$ & البصل \\
\hline $6.033 \mathrm{~b} \mathrm{c}^{*}$ & الثوم \\
\hline $0.0 \mathrm{~d}$ & العنب \\
\hline $4.0 \mathrm{c}$ & الفجل \\
\hline $10.0 \mathrm{a}$ & الفلفل الأحمر \\
\hline
\end{tabular}

* الارقام التي تحمل احرفا متشابهة تدل على عدم وجود فروق معنوية بينها عند مستوى احتمال010.01 حسب اختبار دنكن

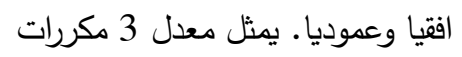

\section{المصادر}

1) Abdullah, Ali Mohammed. Citrus. General Authority for Agriculture and Fisheries Affairs. Agricultural Extension and Information Department. Kuwait. (1993).

2) Directorate of Agricultural Staticstics. Citrus Production Report 2014 Ministry of Planning, Central Bureau of Statics, Republic of Iraq, July2014, p 1-9 (2014).

3) Goto, M. Citrus canker. Plant Diseases of International Importance .III Disease of Fruit Crop. J. kumar, H.S. Chaube, U .S . Singh, and A. S. Singh, and A. N. Mukhopadhyay, eds. Prentice Hall, Englewood Cliffs, NJ. (1991). 
4) Obeidi, Ahmed Nabil Said. Study of Bladder Disease on Pear and Apple. Master Thesis, Faculty of Agriculture, Mosul University, Iraq (2017).

5) Majid, Guitar Rashid and Sabah Malik Habib Al - Shatti. Effectiveness of some plant extracts on the growth of some microorganisms. Basra Agricultural Sciences (2002).

6) Wells, john m boligala c. raju, hsueh-yun hung, william g. weisburg, linda mandelco - Paul, and don j. Brenner. Xylella fastidiosa gen. nov., sp. nov: gram-negative, xylem - limited, fastidious plant bacteria related xanthomonas spp. international journal of systematic bacteriology, Ap Vol.37,no.2p.136143(1987).

7) Alwakil, Mohamed Abdel Rahman, Book of Plant Pathology, Integrated Development of Agricultural Programs in Plant Production, Arab Library, Mansoura University, Egypt. P 17 (2006).

8) Holt, J.C. and N. R. king. Berge's Manual of Systematic Bacteriology. Vol. William and Wilkins London (1986).

9) Suk Park, Dong, Jae Wook Hyun, HeeWan Kang. Sensitive and specific detection of xanthomonas axonopodis $p v$. citri by PCR using pathovar specific primers based hrpw gene sequences MicrobiologicalResearch161P:145-149 (2006).

10) Gent, D. H., Al-Saadi, A., Gabriel, D. W., Louws, F. J., Ishimaru, C.A., and Schwartz, H. F. Pathogenic and genetic relatedness among Xanthomonas axonopodis pv. allii and other pathovars of $X$. axonopodis Phytopathology 95:918-925( 2005)

11) Bauer A, Kirby W, Sherris JC, turck, Turck M. Antibiotic susceptibili testing by a standardized single disk method. A. J .C. P.;45(4): 493. (1966).

12) Egorove, N. S.: Antibiotics Scientific Approach. Micropublishers'. Moscow. (1985).

13) Islam MA, Mazumdar RM, Islam S, Alam MJ, Urmee SA. Isolation, identification and in-vitro antibiotic sensitivity pattern of citrus canker causing organism Xanthomonas axonopodis. Adv. life sci., 1(4): 215-222(2014).

14) Minsavage, G.V. Cantevos, B.I., and stall, R. E. (1990). Plasmid - mediated resistance to streptomycin in Xanthomonas campestris pv. Vesicarotia. phytopathology.80: $719-723$.

15) Alani, Fayez Aziz, Amin Salman. Principles of microbiology, Dar L- Hikma for printing and publishing, Mosul, Iraq (1990).

16) Salman, Ali Marzouk, Alaa Idan Hassan. Evalution of the efficacy of plant extracts, antibiotics and bioconcentraction bacteria Bacillus cereus in resistance to mild bacterial fungal disease caused by bacteria. Kufa Journal of Agricultural Sciences/ Volume (3)/ lssue (2) p: 151 - 161 (2011). 